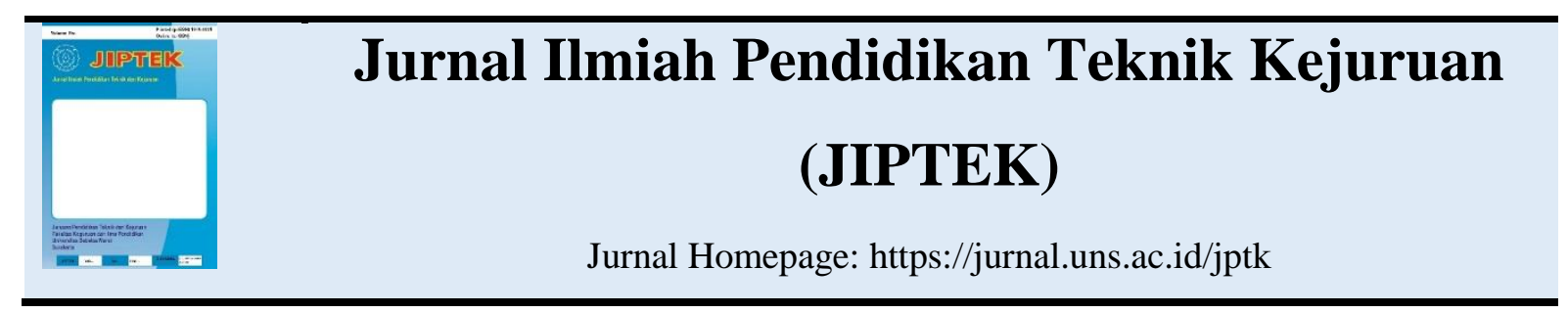

\title{
PEMBUATAN APLIKASI $W E B$ BERBASIS SMS \\ SEBAGAI MEDIA PENYALUR INFORMASI DAN KOMUNIKASI ANTARA SEKOLAH DENGAN ORANG TUA SISWA
}

\author{
Efrem Heri Budiarto, Rosihan Ari Yuana, Dwi Maryono \\ Program Studi Pendidikan Teknik Informatika dan Komputer, Universitas Sebelas Maret \\ Email: ediarto@gmail.com
}

\begin{abstract}
ABSTRAK
Penelitian ini bertujuan untuk menghasilkan sebuah aplikasi yang dapat membantu orang tua dan pihak sekolah dalam hal penyampaian informasi. Aplikasi ini berbasis Web dan SMS (Short Message Service). Aplikasi ini dapat menghubungkan orang tua murid dan sekolah melalui SMS yang dikirim. Penelitian ini dilakukan di SMK Negeri 1 Kudus dengan menggunakan teknik pengumpulan data seperti wawancara, menyebarkan lembar penilaian dan dokumentasi. Model yang digunakan dalam pembuatan Aplikasi Web Berbasis SMS sebagai media penyalur informasi dan komunikasi antara sekolah dengan orang tua siswa adalah Waterfall dengan langkah-langkah sebagai berikut : (1) Communication berupa diskusi awal antara peneliti dengan pihak sekolah. (2) Planning merupakan tahap perancangan kebutuhan software, kebutuhan hardware dan kebutuhan fungsionalitas. (3)Modeling yaitu tahap perancangan aplikasi yang berfokus pada pemrosesan data. Tahap ini dimulai dengan pembuatan Use case Diagram, Flowchart, DFD (Data Flow Diagram), ERD (Entity Relationship Diagram), Desain Tabel dan Relasinya, dan yang terakhir adalah pembuatan Desain Tampilan Aplikasi. (4)Construction yaitu tahap implementasi berdasarkan alur data dan alur aplikasi yang telah dibuat. (5)Deployment merupakan tahap pengujian kepada pihak SMK dengan bimbingan dari peneliti untuk mendapatkan masukan untuk pengembangan aplikasi yang selanjutnya. Hasil dari penelitian ini adalah aplikasi web berbasis SMS yang mampu mempermudah komunikasi antara sekolah dan orang tua siswa dengan hasil pengujian sebagai berikut : Dari ahli sistem 82,4, dari guru dan staf tata administrasi 81,6, dan dari orang tua 79,76. Sehingga dapat disimpulkan bahwa aplikasi ini layak untuk digunakan.
\end{abstract}

Kata Kunci : SMS Gateway, web, penyalur informasi dan komunikasi, SMS

\section{PENDAHULUAN}

Pemberian informasi dari sekolah ke orang tua siswa masih menggunakan surat yang dititipkan kepada siswa. Cara ini memiliki kelemahan yaitu surat yang dititipkan bisa saja tidak sampai atau telat sampai ke orang tua. Untuk mengatasi hal tersebut maka dibuatlah aplikasi web berbasis SMS. Dengan menggunakan web dan SMS diharapkan informasi yang diberikan sekolah ke orang tua siswa atau dari orang tua siswa ke sekolah dapat tersampaikan.

Aplikasi yang berbasis web ini memiliki tujuan agar dapat diakses oleh 
siapa saja dalam 1 jaringan. Web dapat didefinisikan sebagai kumpulan sumber atau informasi yang dihubungkan dengan hyperlinks melalui server HTTP (Hypertext Transfer Protocol) (Prasetyo, 2003:2-3). Sebuah halaman web berisi tag-tag dari bahasa pengkodean yaitu HTML. HTML sendiri bersifat statis sehingga untuk menciptakan sebuah web yang dinamis maka diperlukan bahasa pemrograman PHP dan JavaScript. Hypertext Prepocessor (PHP) atau yang biasa dikenal dengan PHP merupakan sebuah skrip yang akan di proses oleh server dan hasilnya akan ditampilkan ke client melalui browser. Seperti halnya JavaScript, kode PHP dapat disisipkan pada kode HTML. Selain itu PHP juga bisa digunakan untuk menghasilkan kode-kode HTML. (Abdul Kadir, 2009: 246). Pembuatan aplikasi ini menggunakan salah satu framework PHP, yaitu Codeigniter. Codeigniter adalah framework PHP yang mudah digunakan. Banyaknya persamaan antara PHP dan CodeIgniter adalah kelebihan dari CodeIgniter.(Foster, 2013: 2). Penggunaan framework ini bertujuan agar aplikasi dapat dibuat dengan lebih cepat dan juga lebih mumpuni, hal ini dikarenakan sebuah framework memiliki berbagai macam kelengkapan yang dibutuhkan oleh seorang programmer salah satunya adalah keamanan dari sebuah aplikasi yang dibuat.

Aplikasi ini juga mampu menyimpan pesan singkat yang masuk. Pesan ini disimpan pada basis data. Sistem basis data adalah suatu sistem informasi yang mengintregasikan kumpulan dari data yang saling berhubungan satu dengan yang lainya dan membuatnya tersedia untuk beberapa aplikasi yang bermacam-macam di dalam suatu organisasi (Jogiyanto, 2005: 712). Penggunaan basis data ditambah dengan pemrosesan data melalui bahasa pemrograman PHP dapat menghasilkan informasi yang diinginkan.

Penggunaan SMS sebagai media penyalur informasi dan media komunikasi dari aplikasi ini adalah karena SMS merupakan fitur standar yang pasti ada pada semua telepon genggam. Untuk dapat menerima sebuah SMS maka aplikasi ini membutuhkan SMS Gateway. SMS gateway diartikan sebagai suatu jembatan komunikasi yang menghubungkan perangkat komunikasi (dalam hal ponsel) dengan perangkat komputer. (Masruri, 2015: 3). SMS Gateway yang digunakan dalam pembuatan aplikasi ini adalah Gammu. Dengan bantuan SMS Gateway ini maka aplikasi ini dapat menerima, memproses, dan mengirim pesan SMS.

Berkaitan dengan penggunaan SMS Gateway, Novianti, Ariza. Fauzijah, Ami (2009) melakukan penelitian tentang sebuah sistem informasi sekolah yang berbasis SMS. Sistem tersebut telah mampu mengenali format SMS yang dikirimkan user. Apabila user tidak mengirimkan SMS 
sesuai format, baik disengaja ataupun tidak maka sistem akan mengirimkan pesan kesalahan. Sedangkan dari sisi user admin sistem juga telah mampu menampilkan pesan kesalahan berupa dialog box apabila admin melakukan kesalahan baik kesalahan input atau kurang tepat dalam mengisikan data. Selain itu SMS servernya, sistem telah mampu menampilkan informasi yang diisikan oleh admin berupa tabel. Sedangkan dari sisi user, sistem telah mampu mengirimkan SMS secara langsung tanpa user orangtua.

Selain itu Setiawan, Budi, dkk. (2012) melakukan penelitian tentang sebuah sistem informasi berbasis SMS Gateway yang berfungsi untuk menyampaikan informasi pada Sekolah Tinggi Keguruan dan Ilmu Pendidikan (STKIP PGRI PACITAN). Peneltian tersebut menghasilkan dengan adanya sistem informasi ini pihak BAAK STKIP PGRI PACITAN lebih mudah dalam penyampaian informasi kepada mahasiswa, selain itu berdasarkan pendapat dari 30 responden dengan berbagai pertanyaan yang meliputi kualitas sistem berbasis SMS, kemampuan sistem demi membantu mendapatkan informasi, tingkat kemudahan dan kecepatan proses Sistem Informasi berbasis SMS gateway dihasilkan bahwa rata-rata $85 \%$ - $90 \%$ responden sangat menyukai sistem informasi berbasis SMS Gateway.
Pada tahun selanjutnya Priyadna, Anjar. Kusuma, Berliana Riasti (2013) melakukan penelitian mengenai pembuatan sistem informasi nilai akademik yang terintegrasi dengan SMS gateway pada SMP Negeri 3 Pringkuku Pacitan. Penelitian tersebut menghasilkan penyampaian nilai hasil belajar siswa di sekolah kepada siswa melalui SMS menjadi lebih mudah dan sesuai dengan tujuan, dan dapat menjalin hubungan baik antara sekolah dengan orang tua siswa bisa di tingkatkan, sehingga perhatian orang tua terhadap pendidikan putra putrinya di sekolah semakin meningkat. Pada tahun yang sama Nurlaela, Fetty (2013) melakukan penelitian mengenai aplikasi SMS gateway yang berfungsi sebagai informasi penunjang perpustakaan pada SMPN 1 Arjosari. Penelitian tersebut menghasilkan aplikasi tersebut dapat membantu petugas perpustakaan dalam mengelola data buku, data member, data transaksi peminjaman dan pengembalian, selain itu dapat memudahkan siswa mengetahui informasi buku perpustakaan penyampaian informasi kepada siswa dapat dilakukan secara otomatis dan lebih efisien.

Masih ditahun yang sama Roni, Jefricha Pradani (2013) melakukan penelitian tentang aplikasi penyampaian informasi warga SMAN 2 Pati yang berbasis SMS gateway. Penelitian tersebut menghasilkan sekolah dapat menyediakan 
informasi untuk Guru atau siswa, secara broadcast. Dengan adanya layanan SMS gateway ini, informasi dapat diterima langsung ke ponsel Guru, Karyawan serta siswa atau orang tua siswa melalui pesan singkat. Pada tahun 2014 Krishna, Anurag, \& Prabhune melakukan penelitian tentang pemberian informasi melalui pesan singkat yang dilakukan di suatu kampus di India. Penelitian ini menghasilkan bahwa penggunan dari aplikasi dapat berkomunikasi dengan pengajar dan institusi lainnya dengan biaya yang tidak terlalu besar, namun dapat mengumpulkan pengetahuan dan informasi dengan lebih maksimal.

Dalam pembuatan aplikasi ini juga dibuat dokumentasi program berupa: (1) Usecase diagram adalah deskripsi paling sederhana tentang fungsi sistem dari sisi user. (2) Flowchart atau bagan alir adalah skema/bagan (chart) yang menunjukkan aliran (flow) di dalam suatu program secara logika. Flowchart merupakan alat yang banyak digunakan untuk menggambarkan algoritma dalam bentu notasi-notasi tertentu. (Mulyanto, 2008:103-104).

DFD (Data Flow Diagram) adalah representasi grafis yang menggambarkan aliran informasi dan perubahan bentuk dari data input ke output. Bentuk dasar dari Data Flow Diagram (DFD), juga dikenal sebagai grafik aliran data atau grafik gelembung. (4) ERD (Entity Relation Diagram) merupakan suatu diagram dalam bentuk gambar atau simbol yang mengidentifikasi tipe dari entitas di dalam suatu sistem yang diuraikan dalam data dengan atributnya, dan menjelaskan hubungan atau relasi diantara entitas tersebut.

\section{METODE PENELITIAN}

\section{Jenis Penelitian}

Penelitian ini menggunakan jenis metode penelitian dan pengembangan (Research and Development) dengan menggunakan model Waterfall untuk menghasilkan aplikasi web berbasis SMS.

\section{Tempat dan Waktu Penelitian}

Penelitian ini dilaksanakan di Laboratorium PTIK FKIP Universitas Sebelas Maret dan SMK Negeri 1 Kudus. Waktu penelitian dilakukan secara bertahap yaitu dimulai bulan April 2016 sampai dengan Juni 2016

\section{Disain Penelitian}

Pembuatan aplikasi ini menggunakan model Waterfall. Model ini cocok digunakan karena kebutuhan dari pengembangan aplikasi yang sudah jelas, aplikasi yang dihasilkan baik dan juga dokumen pengembangan sistem yang dihasilkan lengkap dikarenakan prosesnya yang dilakukan secara bertahap. Model ini terdiri dari communication, planning, modeling, construction, dan deployment seperti pada Gambar 1. 


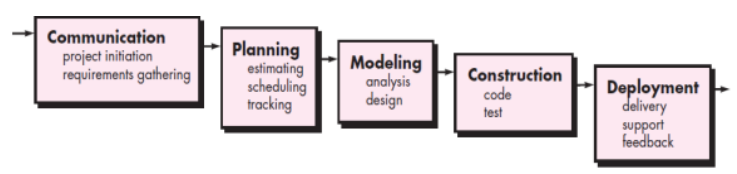

Gambar 1. Alur Model Waterfall

(Sumber:Pressman R. S., 2010:39)

\section{Teknik Pengumpulan Data}

Penelitian ini menggunakan beberapa metode untuk mengetahui atau mendapatkan gambaran tentang masalah yang terjadi di sekolah yang berkaitan dengan penelitian ini. Metode pengumpulan data yang digunakan untuk mendapatkan data pada penelitian ini adalah sebagai berikut: (1) wawancara (2) kuesioner (3) observasi (4) literatur dan studi kepustakaan (5)black box (6) dokumentasi.

\section{Kriteria Penilaian}

Kriteria penilaian aplikasi dapat dilihat pada Tabel 1.

Tabel 1. Pedoman Kriteria Penilaian

\begin{tabular}{cl}
\hline \multicolumn{1}{c}{ Skor } & \multicolumn{1}{c}{ Keterangan } \\
$\leq \mathbf{5 0 , 0 0}$ & $\begin{array}{l}\text { Sangat Tidak } \\
\text { Layak }\end{array}$ \\
\hline $\mathbf{5 0 , 0 1}-\mathbf{6 0 , 0 0}$ & Tidak Layak \\
\hline $\mathbf{6 0 , 0 1}-\mathbf{7 0 , 0 0}$ & Cukup Layak \\
\hline $\mathbf{7 0 , 0 1}-\mathbf{8 0 , 0 0}$ & Layak \\
\hline $\mathbf{8 0 , 0 1}-\mathbf{1 0 0 , 0 0}$ & Sangat Layak \\
\hline
\end{tabular}

\section{HASIL PENELITIAN DAN \\ PEMBAHASAN}

\section{Communication}

Pada tahap ini sebuah project mulai diinisialisasi. Tahap ini dapat menghasilkan berbagai informasi yang dapat berguna untuk menjalankan tahap-tahap selanjutnya.

Berdasarkan wawancara yang telah dilakukan dengan guru dapat diambil kesimpulan bahwa SMK Negeri 1 Kudus sudah pernah memiliki SMS gateway namun sekarang sudah rusak.

Aplikasi Web Berbasis SMS ini diharapkan mampu berjalan dengan baik sehingga pihak sekolah dapat memberikan informasi ke pada orang tua siswa, guru dan karyawan dengan cepat. Selain itu orang tua juga dapat memberikan informasi ke sekolah.

\section{Planning}

Pada tahap planning ini dibuatlah rancangan kebutuhan perangkat lunak, perangkat keras, dan fungsional dari aplikasi. Spesifikasi perangkat lunak yang digunakan untuk membuat aplikasi ini adalah sebagai berikut: (1) Windows 7 dengan level UAC (User Account Control) yang paling rendah. (2) Firefox / GoogleChrome versi terbaru. (3) Minimal PHP versi 5.4. (4) MySQL versi 5.1. Untuk spesifikasi perangkat kerasnya adalah sebagai berikut: (1) 1. Intel Core i3-2350M CPU @ 2,30 GHz. (2) Intel HD Graphics 3000 / NVDIA GeForce 610M (3) Harddisk 600 GB. (4) 4GB RAM. (5) Modem yang terdaftar pada situs resmi Gammu.

Rancangan kebutuhan fungsional dari aplikasi ini adalah sebagai berikut: (1) Aplikasi ini memiliki 2 level pengguna yaitu admin dan operator. (2) Aplikasi ini mampu mengirim pesan singkat secara masal maupun satu per satu. (3) Aplikasi ini dapat menerima SMS. (4) Aplikasi ini mampu 
membalas pesan secara otomatis jika sesuai format. (5) Aplikasi ini mampu menerima izin melalui pesan singkat yang kemudian akan meneruskan pesan tersebut ke guru wali kelas dan juga guru BK. (6) Aplikasi ini mampu menyajikan rekap SMS dan juga siswa yang izin melalui aplikasi.

\section{Modeling}

Tahap ini merupakan sebuah tahap yang dapat menghasilkan rancangan alur data, alur aplikasi, rancangan tabel dan tampilan program.

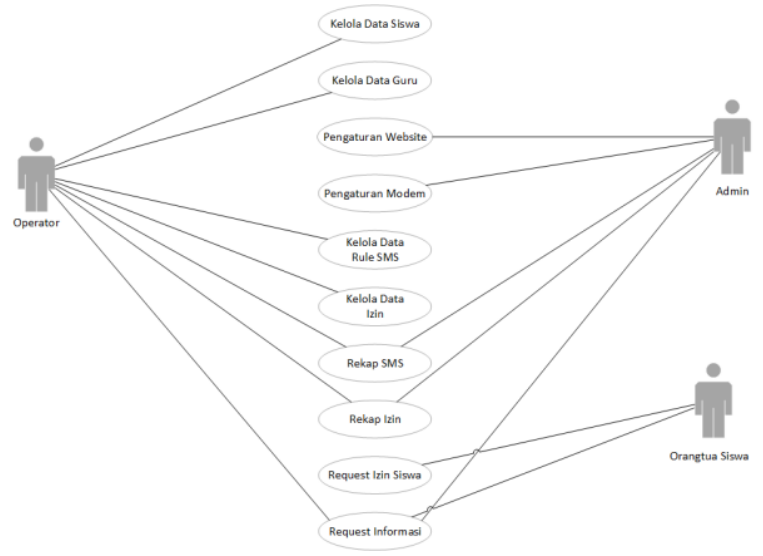

Gambar 2. Usecase Diagram

Tahap modeling dimulai dari pembuatan Usecase Diagram. Kegunaan utama dari usecase diagram adalah untuk menyediakan dokumen/diagram untuk memahami kebutuhan dalam pengembangan sistem informasi (Dennis, Wixom, \& Tegarden, 2005:34). Diagram ini menggambarkan siapa saja user yang menggunakan aplikasi ini berikut juga dengan proses apa saja yang bisa dilakukannya. Gambar 2 merupakan usecase diagram dari aplikasi ini. Pada aplikasi ini pengguna dibagi menjadi tiga jenis yaitu operator, admin, dan orang tua siswa. Operator mampu melakukan berbagai fungsi terkait manajmen data, dan cetak rekap. Admin hanya dapat melakukan pengaturan terkait aplikasi dan juga melihat rekap. Fungsi perminttan informasi dapat dilakukan oleh admin dan juga operator. Orang tua siswa memiliki fungsi khusus yang tidak dimiliki oleh pengguna lainnya, yaitu pemberian informasi izin untuk tidak masuk sekolah.

Selanjutnya flowchart yaitu merupakan alat yang banyak digunakan

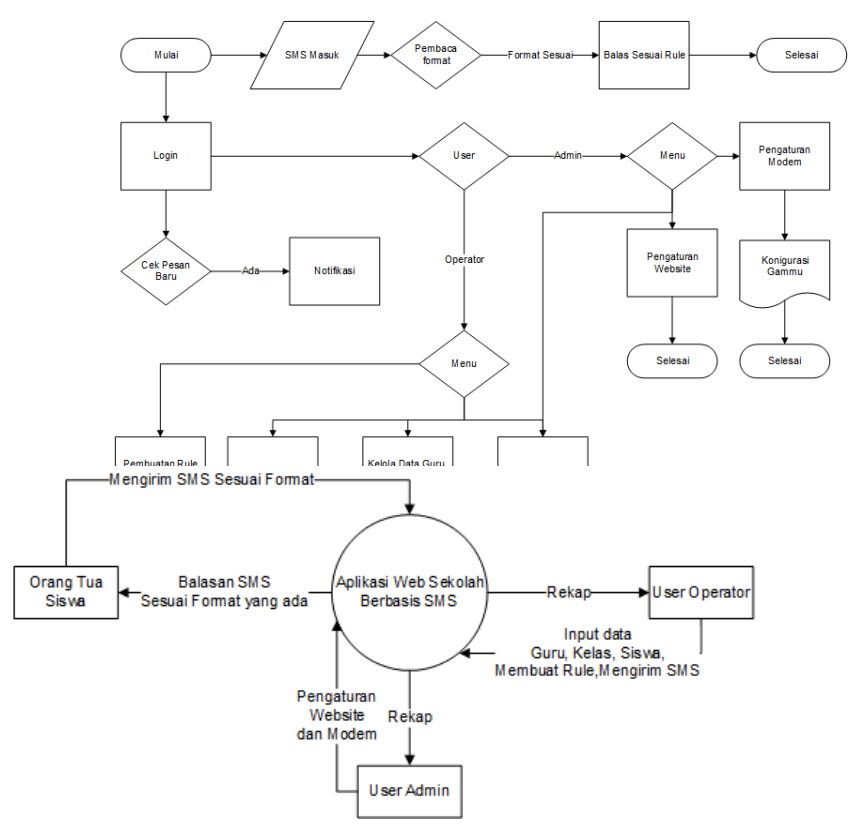

Gambar 4. DFD Level 0

untuk menggambarkan algoritma dalam bentu notasi-notasi tertentu. (Mulyanto, 2008:103-104). Gambar 3 merupakan flowchart dari aplikasi ini. Pada gambar tersebut dijelaskan alur penggunaan secara sederhana mulai dari login hingga selesai. 
Tahap selanjutnya adalah pembuatan DFD (Data Flow Diagram) yang menggambarkan proses apa saja yang terdapat pada aplikasi ini berikut dengan pembagiannya berdasarkan penggunanya. Gambar 4 merupakan gambaran secara umum dari proses, pengguna, dan data yang ada pada aplikasi ini. Setiap pengguna memberikan data dan juga mendapatkan data balikan berupa informasi yang dibutuhkan.

Tahap keempat adalah pembuatan ERD (Entity Relation Diagram) ini menekankan pada struktur dan relationship data. (Munif, 2013: 32). Hasil dari rancangan ERD ini yang nantinya akan menjadi sebuah tabel dalam pembuatan basis data.

Tahap kelima yaitu pembuatan tabel dan relasi, pada tahap ini dibuatlah tabel tabel yang nantinya akan berfungsi sebagai penyimpanan data yang ada pada Aplikasi Web Berbasis SMS ini. Selain pembuatan tabel, pada tahap ini juga diberikan relasi antar tabel yang memang saling berhubungan.

Tahap selanjutnya adalah pembuatan disain tampilan. Tahap ini bertujuan sebagai dasar dalam pembuatan antarmuka aplikasi. Hasil pada tahap ini adalah tampilan untuk halaman login, tampilan untuk halaman konten, dan tampilan untuk halaman rekap.

\section{Construction}

Tahap ini dimulai dari pembuatan antarmuka pengguna. Setelah disain telah dibuat, maka selanjutnya adalah pengembangannya sehingga menjadi antarmuka aplikasi. Pada tahap ini juga muncul beberapa fitur yaitu: (1) Notifikasi SMS Masuk. (2) Cek Pulsa. (3) Membalas SMS Secara Otomatis. (4) Menerima SMS Izin Siswa Melalui dan Meneruskannya ke Guru. (5) Mengirim Beberapa SMS Sekaligus. (6) Mengirim Kembali Pesan yang Gagal Terkirim. (7) Rekap.

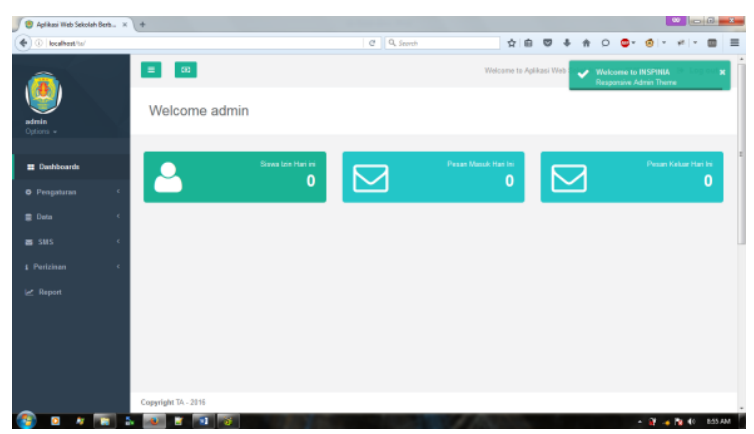

Gambar 5. Halaman Dashboard

Gambar 5 merupakan contoh halaman dashboard atau tampilan awal ketika pengguna berhasil login ke aplikasi. Halaman ini diharapkan dapat memberikan informasi tentang beberapa hal terkait aplikasi. Informasi yang disajikan pada halaman ini adalah beberapa data statistik hari ini, yaitu jumlah siswa yang tidak masuk, jumlah pesan masuk, dan jumlah pesan keluar. 
\#demo\#

terimakasih sudah mengirim sms

6/2/2016 9:20 PM 1

Test pesan singkat

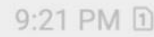

\#test\#

ini adalah balasan pesan otomatis

Gambar 6. Contoh Balasan Otomatis

Gambar 6 merupakan contoh balasan dari aplikasi secara otomatis. Untuk menggunakan fitur ini orang tua cukup mengirimkan SMS dengan format tertentu, kemudian aplikasi akan membalas pesan tersebut sesuai dengan pengaturan yang telah diatur oleh operator. Melalui fitur ini orang tua siswa diharapkan mampu memperoleh informasi terkait kegiatan sekolah dengan lebih mudah dan cepat.

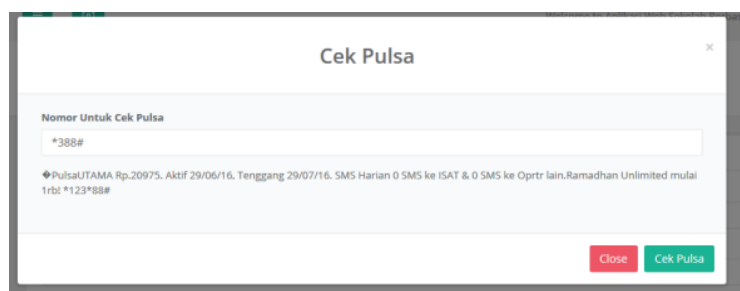

Gambar 7. Fitur Cek Pulsa

Gambar 7 merupakan tampilan dari hasil pengecekan pulsa melalui aplikasi ini. Fitur ini bisa diakses oleh admin maupun

operator. Fitur ini diharapkan mampu memberikan informasi tentang sisa pulsa dan masa tengang dari kartu yang digunakan.

\section{Deployment}

Pada tahap ini aplikasi yang telah dibuat diujikan untuk mendapatkan umpan balik. Pengujian yang dilakukan dibagi menjadi 2 bagian, yaitu pengujian menggunakan metode Black Box dan pengujian dengan ahli.

Pengujian ini dilakukan untuk memastikan apakah aplikasi yang dibuat ini sudah sesuai atau belum, selain itu pengujian ini juga bertujuan untuk menentukan kelayakan dari aplikasi ini.

Tabel 2 berisi penjabaran dari penilaian yang telah dilakukan oleh ahli sistem. Hasil rerata dari perhitungan kumulatif dari setiap aspeknya menghasilkan nilai 82,4 yang berarti bernilai sangat layak karena berada pada rentang 80,01 - 100 .

Tabel 2. Hasil Pengujian Aplikasi oleh Ahli Sistem

\begin{tabular}{llc}
\hline No. & Aspek yang Dinilai & Nilai \\
\hline $\mathbf{1}$ & $\begin{array}{l}\text { Ketepatan pemilihan jenis } \\
\text { aplikasi / software / tools } \\
\text { untuk pengembangan }\end{array}$ & 93 \\
\hline $\mathbf{2}$ & Kemudahan Akses & 80 \\
\hline $\mathbf{3}$ & Proses dan Aliran Data & 77 \\
\hline $\mathbf{4}$ & Tampilan Program & 72 \\
\hline $\mathbf{5}$ & Keberlanjutan Program & 90
\end{tabular}

Rerata 82,4

Tabel 3 berisi penjabaran dari penilaian yang telah dilakukan oleh guru dan 
staf tata usaha. Hasil rerata dari perhitungan kumulatif dari setiap aspeknya menghasilkan nilai 81,6 yang berarti bernilai sangat layak karena berada pada rentang 80,01 - 100 .

Tabel 3. Hasil Pengujian Aplikasi oleh Guru dan Staf Tata Usaha

\begin{tabular}{clc}
\hline No. & \multicolumn{1}{c}{ Aspek yang Dinilai } & Nilai \\
\hline $\mathbf{1}$ & Kesesuaian Sistem & 87 \\
\hline $\mathbf{2}$ & $\begin{array}{l}\text { Kelengkapan data / rekap } \\
\text { data yang dihasilkan }\end{array}$ & 80 \\
\hline $\mathbf{3}$ & Kestabilan progam & 78 \\
\hline Rerata & 81,6 \\
\hline
\end{tabular}

Tabel 4 berisi penjabaran dari penilaian yang telah dilakukan oleh orang tua. Hasil rerata dari perhitungan kumulatif dari setiap aspeknya menghasilkan nilai 79,76 yang berarti bernilai layak karena berada pada rentang 70,01 -80,00.

Tabel 4. Hasil Pengujian Aplikasi oleh

Orang Tua Siswa

\begin{tabular}{lc}
\multicolumn{1}{c}{ Aspek yang Dinilai } & Nilai \\
\hline Fungsionalitas & $\mathbf{7 9 , 7 6}$ \\
\hline Rerata & $\mathbf{7 9 , 7 6}$ \\
\hline
\end{tabular}

\section{SIMPULAN DAN SARAN}

\section{Simpulan}

Berdasarkan hasil penelitian dan pembahasan, maka dapat disimpulkan bahwa (1) pembuatan aplikasi web berbasis SMS ini terdiri dari beberapa tahap yaitu: communication, planning, modeling, construction, dan deployment (2) aplikasi ini layak dengan rincian penilaian seperti berikut: dari ahli sistem sebesar 82,4 , dari ahli substansi sebesar 81,6 dan dari orangtua siswa sebesar 79,76.

\section{Saran}

Berdasarkan kelemahan produk pada kajian produk akhir maka saran yang dapat diberikan untuk langkah pengembangan dan penelitian selanjutnya adalah sebagai berikut: (1) Aplikasi yang dikembangkan dapat terintegrasi dengan penilaian siswa sehingga orangtua siswa dapat melihat perkembangan nilai dari anaknya di sekolah. (2) Membuat tampilan yang lebih menarik lagi. (3) Membuat aplikasi yang mampu terhubung dengan beberapa modem sekaligus. (4) Membuat aplikasi yang mampu menampilkan pesan multipart menjadi satu bagian.

\section{DAFTAR PUSTAKA}

Dennis, A., Wixom, B. H., \& Tegarden, D. (2005). Systems Analysis and Design with UML Version 2.0 'An ObjectOriented Approach'. Hoboken: John Wiley \& Sons, Inc.

Foster, R. (2013). Codeigniter 2 Cookbook. Birmingham: PACKT Publishing Ltd.

Jogiyanto. (2005). Sistem Teknologi Informasi. Yogyakarta: ANDI.

Krishna, V, Prabhune, S. S., \& Anurag, R. (2014). Short messaging service as an alternative for pushing information to build efficient information passing systems in academic institutions. IT in Business, Industry and Government (CSIBIG). IEEE.

Masruri, M. H. (2015). Membangun SMS Gateway dengan Gammu \& Kalkun. Jakarta: PT Elex Media Komputindo.

Mulyanto, A. R. (2008). Rekayasa Perangkat Lunak Jilid 1. Jakarta: Direktorat Pembinaan Sekolah 
Menengah Kejuruan, Direktorat Jenderal Manajemen Pendidikan Dasar dan Menengah, Departemen Pendidikan Nasional.

Munif, A. (2013). Basis Data. Jakarta: Kementerian Pendidikan dan Kebudayaan.

Novianti, A., \& Fauzijah, A. (2009, Juni 20). Sistem Informasi Sekolah Dasar Berbasis SMS. Seminar Nasional Aplikasi Teknologi Informasi, (p. hlm. 6). Yogyakarta.

Nurlaela, F. (2013, Oktober). Aplikasi SMS GATEWAY sebagai Sarana Penunjang Informasi Perpustakaan. Indonesian Journal on Networking and Security, 2(4), 5.

Prasetyo, D. D. (2003). Membangun Web Dinamis di Linux dengan Bluefish. Jakarta: PT Elex Media Komputindo.
Pressman, R. S. (2010). Software Engineering: A Practitioner's Approach,Sevent Edition (Vol. 7). New York: McGraw-Hill.

Priyadna, A., \& Riasti, B. K. (2013). Pembuatan istem Informasi Nilai Akademik Berbasis SMS Gateway. Indonesian Journal on Networking and Security, 2(1), 5.

Roni, J. P., Kusuma, B. R., \& Purnam, B. E. (2013). Pembangunan Aplikasi Sebagai Sarana Penyamapaian. hlm. 13.

Setiawan, B., Maryono, Sukadi, \& Purnama, B. E. (2012). Strategi Kebijakan Pembangunan Aplikasi Penyampaian Informasi. Indonesian Jurnal on Computer Science - Speed (IJCSS) FTI UNSA, hlm. 7. 